\title{
The effects of diesel exhaust pollution on floral volatiles and the consequences for honey bee olfaction
}

Article

Accepted Version

Lusebrink, I., Girling, R. D. ORCID: https://orcid.org/00000001-8816-8075, Farthing, E., Newman, T. A., Jackson, C. W. and Poppy, G. M. (2015) The effects of diesel exhaust pollution on floral volatiles and the consequences for honey bee olfaction. Journal of Chemical Ecology, 41 (10). pp. 904912. ISSN 0098-0331 doi: https://doi.org/10.1007/s10886-0150624-4 Available at https://centaur.reading.ac.uk/43963/

It is advisable to refer to the publisher's version if you intend to cite from the work. See Guidance on citing.

Published version at: http://dx.doi.org/10.1007/s10886-015-0624-4

To link to this article DOI: http://dx.doi.org/10.1007/s10886-015-0624-4

Publisher: Springer Verlag

All outputs in CentAUR are protected by Intellectual Property Rights law, including copyright law. Copyright and IPR is retained by the creators or other copyright holders. Terms and conditions for use of this material are defined in the End User Agreement. 


\section{CentAUR}

Central Archive at the University of Reading

Reading's research outputs online 


\title{
THE EFFECTS OF DIESEL EXHAUST POLLUTION ON FLORAL VOLATILES AND \\ THE CONSEQUENCES FOR HONEY BEE OLFACTION
}

\author{
INKA LUSEBRINK ${ }^{1, *}$ \\ ${ }^{1}$ Centre for Biological Sciences \\ Life Sciences Building 85 \\ University of Southampton \\ Southampton \\ United Kingdom SO17 1BJ \\ e-mail:I.Lusebrink@soton.ac.uk \\ phone: +44(023) 80594258 \\ ROBBIE D. GIRLING ${ }^{1,3}$ \\ ${ }^{1}$ Centre for Biological Sciences \\ Life Sciences Building 85 \\ University of Southampton \\ Southampton \\ United Kingdom SO17 1BJ \\ ${ }^{3}$ Current address:
}

School of Agriculture, Policy and Development

University of Reading

Reading

United Kingdom RG6 6AR

EMILY FARTHING ${ }^{1}$

${ }^{1}$ Centre for Biological Sciences

Life Sciences Building 85

University of Southampton

Southampton

United Kingdom SO17 1BJ 
TRACEY A. NEWMAN ${ }^{2}$

${ }^{2}$ CES

Faculty of Medicine

Institute for Life Sciences

University of Southampton

Southampton

United Kingdom SO17 1BJ

CHRIS W. JACKSON ${ }^{1}$

${ }^{1}$ Centre for Biological Sciences

Life Sciences Building 85

University of Southampton

Southampton

United Kingdom SO17 1BJ

GUY M. POPPY ${ }^{1}$

${ }^{1}$ Centre for Biological Sciences

Life Sciences Building 85

University of Southampton

Southampton

United Kingdom SO17 1BJ 
1 Abstract - There is growing evidence of a substantial decline in pollinators within Europe

2 and North America, most likely caused by multiple factors such as diseases, poor nutrition,

3 habitat loss, insecticides and environmental pollution. Diesel exhaust could be a contributing

4 factor to this decline, since we found that diesel exhaust rapidly degrades floral volatiles,

5 which honey bees require for flower recognition. In this study we exposed eight of the most

6 common floral volatiles to diesel exhaust in order to investigate, whether it can affect volatile

7 mediated plant-pollinator interaction. Exposure to diesel exhaust altered the blend of common

8 flower volatiles significantly: myrcene was considerably reduced, $\beta$-ocimene became

9 undetectable, and $\beta$-caryophyllene was transformed into its cis-isomer isocaryophyllene.

Proboscis extension response (PER) assays showed that the alterations of the blend reduced

the ability of honey bees to recognize it. The chemically reactive nitrogen oxides fraction of diesel exhaust gas was identified as capable of causing degradation of floral volatiles.

Key Words - Floral scent compounds, diesel exhaust, nitrogen oxides, scent degradation, scent recognition, proboscis extension response. 
Since the winter and spring of 2006-7 there have been reports of elevated colony

losses of managed European honey bees (Apis mellifera) in the U.S.A., Europe, the Middle East, and Japan (Abrol 2012; Oldroyd 2007). Furthermore, there is growing evidence of substantial losses of many wild pollinator species worldwide, mainly within Europe and North America (Biesmeijer et al. 2006; Potts et al. 2010). Declines of managed honey bees and wild pollinators may have serious implications, particularly because global food security is considered to be dependent on animal pollination (Abrol 2012). Even though most staple food crops do not require insect pollination (Ghazoul 2005), 35\% of the world crop production for human food depends on pollinators (Klein et al. 2007). Those pollinated crops are particularly important for our food diversity and add nutritional value to our diet (Steffan-Dewenter et al. 2005). Some crops, such as oilseed rape (Brassica napus), are considered self-fertile (Free 1993), but insect pollination can strongly contribute to increased yield and market value (Bommarco et al. 2012). About $73 \%$ of cultivated crop varieties are pollinated by some type of bee, with the European honey bee dominating crop pollination worldwide (Abrol 2012). The drivers behind the global pollinator decline are likely to be multifactorial and include fragmentation and loss of habitat, increased pesticide use, decreased resource diversity, alien species, spread of pathogens, and climate change (Epstein et al. 2013; Kerr et al. 2015;

Oldroyd 2007; Potts et al. 2010, Vanbergen et al. 2013). However, it is unlikely that this is a definitive list, and it is, therefore, important to investigate additional potential stressors that could results in negative effects on bee fitness.

Bees use mixtures of olfactory and visual stimuli to find suitable host plants (Dötterl and Vereecken 2010). They rely mainly on olfactory cues during their initial foraging bouts, and visual cues become more important in host-plant location as bees gain more experience (Dobson 1994). However, floral scent remains an important stimulus for experienced bees, 
since it allows them to discriminate between rewarding and non-rewarding flowers (Dobson 2006; Wright and Schiestel 2009).

Ozone or reactive species, such as hydroxyl and nitroxyl or nitrate radicals, readily react with volatile organic compounds (VOC) (Atkinson and Arey 2003; Calogirou et al. 1999), which contribute to floral scent and could, therefore, impact upon VOC-mediated plant-insect interactions. McFrederick et al. (2008) modelled the dispersion of three common floral scent compounds (linalool, myrcene, and $\beta$-ocimene) under different air pollution scenarios and concluded that increasing pollution levels may impair the recognition of floral scents by pollinators.

In an earlier study we were able to show that diesel exhaust alters the VOC composition of a synthetic floral odour blend (Girling et al. 2013) designed to mimic the oilseed rape (OSR) cultivar Brassica napus, cv. Topas. It consisted of eight compounds, which are behaviourally active in honey bees, mixed in their naturally occurring ratios (Blight et al. 1997). The exposure of the OSR blend to diesel exhaust rendered two compounds undetectable, which significantly reduced the ability of honey bees to recognize the altered floral scent (Girling et al. 2013). Whether such changes deleteriously affect honey bee foraging or foraging by other pollinators that utilise these compounds is currently unknown. Three of the volatile compounds in OSR are floral scent compounds that occur in more than $50 \%$ of seed plants (reviewed by Knudsen et al. 2006).

In order to investigate further the effects of diesel exhaust emissions on floral VOCs and to study whether such effects could be a more widespread phenomenon, we exposed eight of the 12 most common floral scent compounds (Knudsen et al. 2006) to diesel exhaust, none of which are found in OSR, mixed in equal amounts. To investigate if bees that were conditioned to our floral volatile blend were able to still recognize it after they underwent the alterations caused by diesel exhaust, we used the classical conditioning of the proboscis extension reflex (PER; Bitterman et al. 1983; Kuwabara 1957). Additionally, we exposed all 
eight common floral scent compounds individually to diesel exhaust with the intention of determining their possible fate in a diesel exhaust polluted environment. In order to confirm the general mechanism behind the alteration of floral scent components in such an environment, we also exposed all compounds to various concentrations of $\mathrm{NO}_{X}$, since that was the observed mechanism behind the floral scent degradation in our earlier study (Girling et al 2013).

\section{METHODS AND MATERIALS}

Floral Volatile Blend. Based on a review by Knudsen et al. (2006) on the diversity and distribution of floral scent, we selected eight common floral compounds that occur in more than half of all the families of seed plants: $\beta$-Pinene, myrcene, limonene, $\beta$-ocimene, benzaldehyde, $\beta$-caryophyllene, methyl salicylate, and benzyl alcohol (Table 1). We mixed all eight compounds in equal amounts to produce a common floral volatile (CFV) blend.

Floral Volatile Exposures. For the exposures the general procedure was to place $1 \mu \mathrm{L}$ of CFV blend on a filter paper $(2.1 \mathrm{~cm}$ circle, grade $3 \mathrm{MM}$; Whatman plc, Maidstone, UK) and a $4.5 \mathrm{~cm}$ stir bar in a 1000mL glass bottle (VWR International Ltd., West Sussex, UK). To assess the influence of UV light the tests were replicated in both clear and amber glass bottles. The CFV blend was exposed to either ambient air or diesel exhaust at room temperature. The ambient air treatment consisted of a bottle of air collected from the laboratory. Diesel exhaust was collected into the bottle from the exhaust pipe of a Suntom SDE 6500 E diesel generator (Fuzhou Suntom Power Machinery Co., Ltd. Fuzhou, China) for 3min at a flow rate of 1L/min. Bottles were sealed with two layers of Parafilm $\mathbf{M}^{\circledR}$ (Bemis Flexible Packaging, Oshkosh, WI, USA) and a lid. The lid contained a $1 \mathrm{~mm}$ bore hole in its centre to allow 
insertion of the solid-phase microextraction (SPME) fibre holder for the collection of volatiles. The bottle content was mixed with a stir bar at 300rpm. The content of the bottle was sampled after $1 \mathrm{~min}, 30 \mathrm{~min}, 1 \mathrm{~h}$ and $2 \mathrm{~h}$. At each sample time point the SPME fibre was extended into the bottle and exposed to the volatiles for 5min. The SPME fibre was then inserted into the injector of the gas chromatograph linked to the mass spectrometer (GC/MS) and allowed to desorb for $10 \mathrm{~min}$. This $10 \mathrm{~min}$ desorption period was sufficient to clean the SPME fibre so that the same fibre could be used to collect VOCs from the same bottle and filter paper at a later time point. After the collection of VOC at all four time points the bottle was cleaned with hexane, dried under nitrogen gas, and left in the fume hood overnight to remove the hexane residue. Each of the air treatment and bottle type combinations were repeated five times at room temperature for each of the two floral blends.

Floral Blend GC/MS Analyses. After each VOC adsorption period the SPME fibre assembly (65 $\mu \mathrm{m}$ PDMS/DVB, fused silica, 24Ga, manual holder; Supelco, Bellefonte, PA, USA) was injected into a Hewlett Packard HP6890/5972A GC/MS at an injection port temperature of $250^{\circ} \mathrm{C}$ and a split ratio of $10: 1$. The GC/MS was equipped with a SPME injection sleeve (I.D. 0.75mm, Supelco) and HP-Innowax column (I.D. 0.25mm, length 30m; film thickness $0.25 \mu \mathrm{m}$; Agilent Technologies, Santa Clara, CA, USA). The helium carrier gas flow was set at $1.0 \mathrm{~mL} / \mathrm{min}$, and the oven temperature was held for $2 \mathrm{~min}$ at $50^{\circ} \mathrm{C}$, increased to $70^{\circ} \mathrm{C}$ by $5^{\circ} \mathrm{C}$ per min and then ramped up to $240^{\circ} \mathrm{C}$ by $10^{\circ} \mathrm{C} / \mathrm{min}$.

Peaks were identified using the same standards used to produce the floral volatile blends (Table 1). Isocaryophyllene the rearrangement product of $\beta$-caryophyllene, was identified based on catalytic conversion of $\beta$-caryophyllene in clove oil following US patent 3621070 (Rachlin 1971). 
Preparation of Bees. Honey bees were kept on the University of Southampton campus in an apiary $\left(50^{\circ} 56^{\prime} 10^{\prime \prime} \mathrm{N}, 1^{\circ} 23^{\prime} 39^{\prime \prime} \mathrm{W}\right)$. During the summers of 2012 and 2013, on days when bees showed high activity, 30-35 returning forager bees were caught at their hive entrance between 14:00-16:00 GMT. Bees were caught in Sterilin 30mL universal containers (Sterilin Limited, Cambridge, UK) and kept individually. They were immobilized on ice and transferred into blue $1 \mathrm{~mL}$ pipette tips that were cut to resemble the PER tubes used by Bitterman et al. (1983) and harnessed to it with two strips of cloth tape (tesa ${ }^{\circledR}$ extra Power Perfect). Harnessed bees could freely move their antennae, mouth parts and forelegs (Fig. 1). The PER tubes containing bees were kept in Eppendorf centrifuge tube racks placed inside plastic boxes with perforated lids. The bottom of the box was lined with wet tissue to provide humidity and prevent the bees from desiccating. The bees were fed with a $30 \%$ sucrose solution between 16:00-18:00 and kept in an environmentally controlled room at $20^{\circ} \mathrm{C}$ overnight. PER assays were conducted the next morning for which bees were equally divided into groups of 7-10 bees (depending on overnight survival).

Proboscis Extension Response Assay. One harnessed bee at a time was placed in the experimental arena $(\mathrm{W} \times \mathrm{D} \times \mathrm{H}=60 \mathrm{~cm} \times 45 \mathrm{~cm} \times 55 \mathrm{~cm}) 3 \mathrm{~cm}$ in front of an odour delivery system. Behind the bee, an extraction fan removed the odour from the arena in order to avoid a buildup of any stimuli. The odour delivery system was custom-built. It allowed for a constant stream of fresh air in the arena through Teflon tubing which flowed into a glass tube. The conditioning stimuli were delivered though a three channel system that ended in the same glass tube as the fresh air, before it discharged into the arena. All three channels consisted of electronic valves and Teflon tubing connected to $10 \mathrm{~mL}$ glass tubes, in which the stimuli were placed on a piece of filter paper. One channel served as the control (clean air), which was always open when no volatiles were delivered. In order to deliver scented air, the control channel was switched. The airflow passing through the odour delivery part of the system was 
set at $300 \mathrm{~mL} / \mathrm{min}$ and the fresh air at $200 \mathrm{~mL} / \mathrm{min}$ air. Hence, the bees were constantly exposed to an airflow of $500 \mathrm{~mL} / \mathrm{min}$. The following timeline applied to the PER assay: A bee was allowed to adapt to the experimental arena for $10 \mathrm{~s}$, then was presented with the conditioning stimulus (CS) for 10s. Five seconds after the onset of CS, the antennae of the bee was touched with a cocktail stick that was dipped in $30 \%$ sucrose solution (unconditioning stimulus (US)). Upon extension of her proboscis, the bee was allowed to feed on the sucrose solution for the remaining part of the 10s US period. The bee was then removed from the arena. Thirty seconds was allowed between bees to give the extraction fan additional time to clear the experimental area from any remaining odours.

The bees were conditioned six times to the CFV blend. During these conditioning trials most bees learned to associate the sugar reward with the odour stimuli. Bees which had learned to extend their proboscis in response to the odour stimuli by the sixth conditioning trial were used in the subsequent recognition trials. The recognition trial resembled the conditioning trial but without the use of the US. Its purpose was to test the proboscis response of the bees to the original flower blends and to three different test stimuli for each blend (Table 2). The test stimuli were based on the original blend but some chemical compounds were omitted based on our results from the floral volatile exposure experiment. Extension of the proboscis in response to the test stimulus was rated as a positive recognition. The PER assay was repeated until $n \geq 25$ was achieved for each test group of bees. The results show the percentage of bees that had successfully learned to recognize the floral odour blends and then responded to either of the test stimuli.

Fate of Individual Floral Volatiles. The floral volatile exposure method described above was altered slightly when investigating the fate of all individual compounds as these analyses were conducted on a replacement Agilent Technologies 7890B/5977A GC/MS. Because of its higher sensitivity only $0.2 \mu \mathrm{L}$ of each compound was placed on a filter paper and transferred 
into an amber bottle with either ambient air or diesel exhaust. The content of the bottle was sampled after 30min, and the SPME fibre was exposed to the volatile for $1 \mathrm{~min}$. The SPME fibre was then inserted into the injection port of the GC/MS at $250^{\circ} \mathrm{C}$ and a split ratio of 10:1. The GC/MS was equipped with a SPME injection sleeve, a HP-Innowax column (I.D.

$0.25 \mathrm{~mm}$, length $30 \mathrm{~m}$; film thickness $0.25 \mu \mathrm{m}$ ) and a retention gap (I.D. $0.18 \mathrm{~mm}$, length $4.1 \mathrm{~m}$, film thickness $0 \mu \mathrm{m}$; both Agilent Technologies, Santa Clara, CA, USA). The helium carrier gas flow and oven temperature programme remained the same as for the floral blend analyses described above.

Diesel Exhaust Measurements. In order to determine the concentration of toxic and reactive gases in our diesel exhaust we used a Wolfsense TG501 probe equipped with $\mathrm{O}_{2}, \mathrm{NO}, \mathrm{NO}_{2}$, $\mathrm{SO}_{2}$, and CO photochemical sensors (GrayWolf Sensing Solutions, Shelton, CT, USA). Diesel exhaust was pumped through the probe at a flow rate of $1 \mathrm{~L} / \mathrm{min}$ by attaching a calibration hood. Measured values were logged every 30s. Five 3 min measurements were taken to mimic the diesel exhaust collection for floral volatile exposures.

Influence of Nitrogen Oxides. For the exposures to nitric oxides $\left(\mathrm{NO}_{X}\right)$ a filter paper with $1 \mu \mathrm{L}$ of the CFV blend and a stir bar were added to an amber $1000 \mathrm{~mL}$ bottle. Nitrogen oxides were produced by reducing nitric acid with elemental copper, which resulted in a 1:1 ratio of NO and $\mathrm{NO}_{2}$, which was confirmed by the Wolfsense TG501 probe. Concentrations of 20ppm, 2ppm, $0.2 \mathrm{ppm}$ per bottle were achieved by using gas tight syringes and volumetric calculations. The bottle was closed with two layers of Parafilm $\mathrm{M}^{\circledR}$ and a lid. The content was allowed to stir for 30min at 300rpm before the SPME fibre was extended into the bottle. SPME exposure and the GC/MS method were the same as for floral blend volatile exposures. 
Statistical Analysis. As we found that UV light had no statistically significant effect on the composition of volatiles in our experiments, we pooled the data gained from exposures in amber and clear glass bottles. Due to the large number of samples for the floral volatile exposures, it was necessary to use more than one SPME fibre, which did not allow comparative statistical analyses based on peak area according to the SPME guidelines of the journal. However, the SPME fibres used were from the same lot, and the peak area data of the floral volatile exposures had less variance than that of the $\mathrm{NO}_{X}$ exposure data that was collected using a single SPME fibre. Therefore, we plotted the peak areas as bar graphs with 95\% confidence interval error bars, which provides a graphical display of the significance of differences of the CFV blend when exposed to either ambient air or diesel exhaust (Fig. 6, online supplementary material).

The PER assay data was analysed by comparing the recognition of each test stimuli to the response of bees to the complete CFV blend. Pairwise comparisons were made using $\chi^{2}$ tests. The criterion for significance was corrected after Bonferroni: $\alpha^{\prime}=\alpha / \mathrm{k}$, where $\mathrm{k}$ is the number of comparisons.

The influence of $\mathrm{NO}_{X}$ on the CFV blend was measured with the same SPME fibre, so we were able to directly compare the effect of the different $\mathrm{NO}_{X}$ concentrations on the abundance of compounds. The peak area data was analysed with a MANOVA followed by univariate ANOVAs for each compound and Tukey post-hoc tests for comparing the influence of different $\mathrm{NO}_{X}$ concentrations on the single compounds. All statistical analyses were conducted with SPSS 20.0 for Windows (IBM Corporation, Armonk, New York, USA). 
Floral Volatile Exposures. At the one minute time point of diesel exhaust exposure of the CFV blend the compounds myrcene, $Z$ - and $E$ - $\beta$-ocimene were drastically reduced, and $\beta$-caryophyllene started to be transformed into its cis-isomer, isocaryophyllene (Fig. 2). After 30min, when all compounds in the mixture had reached equilibrium in the glass bottle, myrcene remained strongly reduced, whereas $Z$ - and $E$ - $\beta$-ocimene (assignment of geometrical isomers followed Babushok et al. 2011) became undetectable, and $\beta$-caryophyllene was completely transformed into isocaryophyllene.

Proboscis Extension Response Assays. The recognition assay for the CFV blend revealed that the PER response of the honey bees was significantly influenced by the test stimuli composition. The original CFV blend was recognized by $93 \%$ of all bees in the absence of a sugar reward (Fig. 3). The CFV blend without $\beta$-ocimene (CFV-1) was still recognized by $76 \%$ of bees compared to the original blend, which is non-significant $\left(\chi^{2}(1)=2.928, \mathrm{P}=\right.$ 0.092). Omission of myrcene (CFV-2) had a significant effect on the bees' PER response, and only $37 \%$ still recognized the test stimuli $\left(\chi_{(1)}^{2}=18.941, \mathrm{P}<0.001\right)$. The test stimuli which lacked $\beta$-ocimene and myrcene (CFV-3) was recognized by $39 \%$ of the bees, which is significantly lower than the recognition of the full CFV blend $\left(\chi_{(1)}^{2}=17.923, \mathrm{P}<0.001\right)$.

Fate of Individual Floral Volatiles. Investigation on the effect of diesel exhaust on each single floral volatile showed that $\beta$-caryophyllene was transformed into its $c i s$-isomer, confirming the results that we had seen when we exposed the complete CFV blend to diesel exhaust. These further investigations revealed that the $\beta$-caryophyllene standard sample also contained $\alpha$-copaene and $\alpha$-humulene as impurities (verified by standard injection). The amount of both of them was also drastically reduced after being exposed to diesel exhaust (see supplementary material, Fig. 6), however, we were unable to identify any degradation products. Similarly, we 
could not trace the fate of myrcene and $\beta$-ocimene, the two acyclic monoterpenes in the CFV blend. Benzyl alcohol was partly oxidized to benzaldehyde.

Diesel Exhaust Measurement. The averages of all measurements of all toxic and reactive gases \pm S.E. acquired with the Wolfsense TG501 probe are given in Table 3. Carbon monoxide represented the biggest fraction of the emission gases. Within the $\mathrm{NO}_{X}$ fraction, $\mathrm{NO}$ and $\mathrm{NO}_{2}$ were produced approximately at a ratio of 1:1. No sulphur dioxide was detected which is most likely due to the fact that we used low sulphur diesel.

Influence of Nitrogen Oxides. The abundances of myrcene, $Z$ - $\beta$-ocimene, $E$ - $\beta$-ocimene, $\beta$ caryophyllene, and benzyl alcohol were altered significantly by $\mathrm{NO}_{X}$ (Table 4). In particular, the abundances of myrcene, $Z$ - $\beta$-ocimene, $E$ - $\beta$-ocimene, $\beta$-caryophyllene, and benzyl alcohol were significantly reduced when exposed to $20 \mathrm{ppm} \mathrm{NO}_{X}$ (Fig. 4). The conversion of $\beta$ caryophyllene into isocaryophyllene began at a concentration of $0.2 \mathrm{ppm} \mathrm{NO}_{X}$.

\section{DISCUSSION}

Exposure to diesel exhaust led to a reduction of myrcene in the CFV blend, $\beta$-ocimene disappeared, and $\beta$-caryophyllene was converted into its cis-isomer, isocaryophyllene. Investigations on nitration mechanisms have shown that the reaction of unsaturated compounds with nitrogen dioxide, which is abundant in diesel exhaust, can lead to cis/transisomerization (Augusto et al. 2002; Titov 1963). In the blend used for the behavioural recognition assays we omitted myrcene and $\beta$-ocimene. The lack of $\beta$-ocimene did not influence the recognition of the test stimulus significantly. When myrcene was absent, recognition decreased significantly to only $37 \%$. Similarly, when both compounds were 
missing $39 \%$ of honey bees recognized the test stimuli, suggesting that the absence of myrcene predominantly contributes to the lack of recognition. Similarly, Reinhard et al. (2010) identified myrcene as a key odorant and ocimene as a non-key odorant in the recognition of complex scent mixtures by honey bees. Isocaryophyllene was not available for the behavioural assays, however, we hypothesise that the change from $\beta$-caryophyllene to isocaryophyllene could also have changed the insects' odour perception of the CFV blend. Geometric isomers may differ in their quality of odour (Roderick 1966), e.g. to humans, the cyclic sesquiterpene $(E)$ - $\gamma$-bisabolene smells soapy and spicy, whereas the odour of $(Z)-\gamma$ bisabolene is described as fatty and woody (Kjeldsen et al. 2003). The discrimination of geometric isomers by insects has been mainly studied in the context of straight chain sexpheromones of moths (e.g. Klun et al. 1973; Naka et al. 2013; Silverstein and Young 1976). Investigations into the fates of individual flower volatiles could not detect substantial amounts (if any) of degradation products of the acyclic terpenes myrcene and $\beta$-ocimene. On their oxidative way to carbon dioxide, most biogenetic volatiles pass acetone and formaldehyde (Atkinson and Arey 2003), which, due to their low boiling points, would have been difficult to find by our analytical method. However, primary oxidation products of myrcene such as 4-methylene-5-hexenal and of $\beta$-ocimene such as 4-methyl-3,5-hexadienal (Lee et al. 2006, Reissell et al. 2002) should have been reliably registered.

Each of the floral scent compounds used in our study that degraded when exposed to diesel exhaust also occur in numerous other plant families: $\beta$-caryophyllene in 52\% (46 families), $\beta$-ocimene in $71 \%$ ( $E$ - $\beta$-ocimene in 64 families and $Z$ - $\beta$-ocimene in 44 families), and myrcene in $70 \%$ (63 families) of all investigated seed plant families (Knudsen et al. 2006). Half of the highly ubiquitous flower scent compounds that we tested experienced significant reduction as a result of exposure to diesel exhaust, indicating that it has the potential to disrupt and modify plant floral volatile signalling at a broad scale. 
Diesel exhaust emissions have received considerable attention due to their health risks and environmental concerns, the main focus has been on particulate matter and $\mathrm{NO}_{X}$ (Setiabudi et al. 2004), which are considered to be the main air pollutants of diesel exhaust together with carbon monoxide and hydrocarbons. The $\mathrm{NO}_{X}$ concentrations of our diesel exhaust were approximately 20ppm for both $\mathrm{NO}$ and $\mathrm{NO}_{2}$. When we exposed the floral volatiles to $20 \mathrm{ppm} \mathrm{NO}_{X}$ we observed that it had a similar effect as diesel exhaust: $\beta$ caryophyllene was turned into isocaryophyllene, the amount of myrcene was reduced, $\beta$ ocimene was reduced as well, but still detectable, whereas it had completely disappeared when exposed to diesel exhaust. In contrast to oxygenation involving oxygen species, radical reactions induced by $\mathrm{NO}_{X}$ appear to be responsible for the majority of the changes observed in our CFV blend when exposed to diesel exhaust. In addition, the particulate matter in diesel exhaust may have yet unknown adsorptive and catalytic properties. Because of their isoprene (butadiene) substructure, myrcene and $\beta$-ocimene are particularly labile, and radical reactions may easily cause polymerisation, leading to products that would escape our analytical system. Ambient air quality standards in the EU (ec.europa.eu) and the US (www.epa.gov) suggest a maximum hourly average $\mathrm{NO}_{2}$ concentration of $0.1 \mathrm{ppm}$, a concentration at which $\beta$ caryophyllene started turning into isocaryophyllene in this study, and $\alpha$-terpinene and phenylacetaldehyde were already significantly degraded, in our previous study. Furthermore, in 2013 the UK Supreme Court declared that the nitrogen dioxide limits are regularly exceeded in 16 zones across the UK (European Commission, press release).

Ambient $\mathrm{NO}_{X}$ levels can exhibit strong diurnal patterns, with maximum values in the early morning and another increase in the late afternoon (Fuentes et al. 2007), following periods of high traffic. Fluctuating $\mathrm{NO}_{X}$ levels will change the ratio of compounds in floral scent throughout the course of the day (McFrederick et al. 2008). Additionally, high $\mathrm{NO}_{X}$ levels lead to increased ozone levels (Fehsenfeld et al. 1992), which may further contribute to the degradation of floral scent. Changing floral scent of a flower can cause floral-constant 
pollinators, like honey bees, to reject the flower (Wright and Schiestl 2009), which may impact on pollination efficiency. To date, there is only little research on how air pollution directly impedes on plant-insect interactions. Fuentes et al. (2013) found that ozone pollution obstructs host finding in the cucumber beetle (Acalymma vittatum). Pinto et al. (2007a; 2007b; 2008) investigated the impacts of ozone on tritrophic interactions under both laboratory and field conditions. They showed that parasitoids are able to use herbivore-induced plant VOCs to find their hosts in the presence of ozone, but preferred the intact signal over the ozonedegraded signal. There is also a possibility that the reaction products of floral scent compounds with ozone and other air pollutants might form new compounds that may serve as novel signals (McFrederick et al. 2009).

Our study demonstrates that $\mathrm{NO}_{X}$ and/or other components of diesel exhaust are capable of degrading floral signals and have the potential to alter floral recognition. How this impacts upon the fitness of pollinators requires further investigations, however it has been proposed that pollinators in polluted areas may need to spend more time searching for adequate host plants, which if true could lead to decreased fitness and decreased pollination rates (McFrederick et al. 2008).

\section{Acknowledgements}

We acknowledge Wittko Francke for his valuable comments on the manuscript, Christine M. Reitmayer for her help with beekeeping. We would also like to thank the Erbilgin lab at the University of Alberta for providing us with a trans-verbenol mass spectrum. Funding for this research has been provided through the Leverhulme Trust Research Project Grant RPG-089.

Abrol DP (2012) Decline in pollinators. In: Pollination Biology: Biodiversity Conservation and Agricultural Production. Springer, Netherlands, pp 545-601 doi:10.1007/978-94-0071942-2_17

Atkinson R, Arey J (2003) Gas-phase tropospheric chemistry of biogenic volatile organic compounds: a review. Atmospheric Environment 37, Supplement 2:197-219 doi:10.1016/s1352-2310(03)00391-1 
Augusto O, Bonini MG, Amanso AM, Linares E, Santos CCX, De Menezes SL (2002) Nitrogen dioxide and carbonate radical anion: two emerging radicals in biology. Free Radical Bio Med 32:841-859 doi:10.1016/S0891-5849(02)00786-4

Babushok VI, Linstrom PJ, Zenkevich IG (2011) Retention indices for frequently reported compounds of plant essential oils. J Phys Chem Ref Data 40:043101 doi:10.1063/1.3653552

Biesmeijer JC, Roberts SPM, Reemer M, Ohlemüller R, Edwards M, Peeters T, Schaffers AP, Potts SG, Kleukers R, Thomas CD, Settele J, Kunin WE (2006) Parallel declines in pollinators and insect-pollinated plants in Britain and the Netherlands. Science 313:351-354 doi:10.1126/science. 1127863

Bitterman ME, Menzel R, Fietz A, Schafer S (1983) Classical conditioning of proboscis extension in honeybees (Apis mellifera). J Comp Psychol 97:107-119

Blight MM, Métayer ML, Pham-Delègue MH, Pickett JA, Marion-Poll F, Wadhams LJ (1997) Identification of floral volatiles involved in recognition of oilseed rape flowers, Brassica napus by honeybees, Apis mellifera. J Chem Ecol 23:1715-1727 doi:10.1023/B:JOEC.0000006446.21160.c1

Bommarco R, Marini L, Vaissière B (2012) Insect pollination enhances seed yield, quality, and market value in oilseed rape. Oecologia 169:1025-1032 doi:10.1007/s00442-012-2271-6

Calogirou A, Larsen BR, Kotzias D (1999) Gas-phase terpene oxidation products: a review. Atmos Environ 33:1423-1439 doi:10.1016/s1352-2310(98)00277-5

Dobson HEM (1994). Floral volatiles in insect biology. In: Bernays EA (ed) Insect-plant interactions. CRC Press, London. pp. 47-81.

Dobson HEM (2006) Relationship between floral fragrance composition and type of pollinator. In: Dudareva N and Pichersky E (eds) Biology of Floral Scent. CRC Press, pp 147198 doi:10.1201/9781420004007.sec4

Dötterl S, Vereecken NJ (2010) The chemical ecology and evolution of bee-flower interactions: a review and perspectives. Can J Zool 88:668-697 doi:10.1139/Z10-031

[ec.europa.eu] European Commission press release: Environment: Commission takes action against UK for persistent air pollution problems. http://europa.eu/rapid/press-release_IP-14154_en.htm

Epstein D, Frazier JL, Purcell-Miramontes M, Hackett K, Rose R, Erickson T, Moriarty T, Steeger T (2013) USDA: Report on the national stakeholders conference on honey bee health. http://www.usda.gov/documents/ReportHoneyBeeHealth.pdf. Accessed 27 August 2015

Fehsenfeld F, Calvert J, Fall R, Goldan P, Guenther AB, Hewitt CN, Lamb B, Liu S, Trainer M, Westberg H, Zimmerman P (1992) Emissions of volatile organic compounds from vegetation and the implications for atmospheric chemistry. Global Biogeochemical Cycles 6:389-430 doi:10.1029/92GB02125

Fuentes J, Wang D, Bowling D, Potosnak M, Monson R, Goliff W, Stockwell W (2007) Biogenic hydrocarbon chemistry within and above a mixed deciduous forest. J Atmos Chem 56 (2):165-185 doi:10.1007/s10874-006-9048-4

Fuentes JD, Roulston TaH, Zenker J (2013) Ozone impedes the ability of a herbivore to find its host. Environ Res Letters 8 (1):014048 doi:10.1088/1748-9326/8/1/014048

Free JB (1993) Insect pollination of crops. 2nd edn. Academic Press, London; New York

Ghazoul J (2005) Buzziness as usual? Questioning the global pollination crisis. Trends Ecol Evol 20:367-373 doi:10.1016/j.tree.2005.04.026 
Girling RD, Lusebrink I, Farthing E, Newman TA, Poppy GM (2013) Diesel exhaust rapidly degrades floral odours used by honeybees. Sci Rep doi:10.1038/srep02779

Kerr JT, Pindar A, Galpern P, Packer L, Potts SG, Roberts SM, Rasmont P, Schweiger O, Colla SR, Richardson LL, Wagner DL, Gall LF, Sikes DS, Pantoja A (2015) Climate change impacts on bumblebees converge across continents Science 349:177-180 doi:10.1126/science.aaa7031

Kjeldsen F, Christensen LP, Edelenbos M (2003) Changes in Volatile Compounds of Carrots (Daucus carota L.) During Refrigerated and Frozen Storage J Agr Food Chem 51:5400-5407 doi:10.1021/jf030212q

Klein A-M, Vaissière BE, Cane JH, Steffan-Dewenter I, Cunningham SA, Kremen C, Tscharntke T (2007) Importance of pollinators in changing landscapes for world crops. P Roy Soc Lond B Bio 274:303-313 doi:10.1098/rspb.2006.3721

Klun JA, Chapman OL, Mattes KC, Wojtkowski PW, Beroza M, Sonnet PE (1973) Insect Sex Pheromones: Minor Amount of Opposite Geometrical Isomer Critical to Attraction Science 181:661-663 doi:10.1126/science.181.4100.661

Knudsen J, Eriksson R, Gershenzon J, Ståhl B (2006) Diversity and distribution of floral scent. Bot Rev 72:1-120 doi:10.1663/0006-8101(2006)72[1:dadofs]2.0.co;2

Kuwabara M (1957) Bildung des bedingten Reflexes von Pavlovs Typus bei der Honigbiene, Apis mellifica. Journal of the Faculty of Science, Hokkaido University, Series 6, Zoology, $13: 458-464$

Lee A, Goldstein AH, Keywood MD, Gao S, Varutbangkul V, Bahreini R, Mg NL, Flagan RC, Seinfeld JH (2006) Gas-phase products and secondary aerosol yields from the ozonolysis of ten different terpenes. J Geophysical Res Atmospheres 111 doi: 10.1029/2005JD006437

McFrederick QS, Fuentes JD, Roulston T, Kathilankal JC, Lerdau M (2009) Effects of air pollution on biogenic volatiles and ecological interactions. Oecologia 160:411-420 doi:10.1007/s00442-009-1318-9

McFrederick QS, Kathilankal JC, Fuentes JD (2008) Air pollution modifies floral scent trails. Atmos Environ 42:2336-2348 doi:10.1016/j.atmosenv.2007.12.033

Naka H, Suzuki T, Watarai T, Horie Y, Mochizuki F, Mochizuki A, Tsuchida K, Arita Y, Ando T (2013) Identification of the sex pheromone secreted by Synanthedon tenuis (Lepidoptera: Sesiidae) Appl Entomol Zool 48:27-33 doi:10.1007/s13355-012-0148-0

Oldroyd BP (2007) What's killing American honey bees? PLoS Biol 5:e168 doi:10.1371/journal.pbio.0050168

Pinto D, Blande J, Nykänen R, Dong W-X, Nerg A-M, Holopainen J (2007a) Ozone degrades common herbivore-induced plant volatiles: Does this affect herbivore prey location by predators and parasitoids? J Chem Ecol 33:683-694 doi:10.1007/s10886-007-9255-8

Pinto D, Nerg A-M, Holopainen J (2007b) The role of ozone-reactive compounds, terpenes, and green leaf volatiles (GLVs), in the orientation of Cotesia plutellae. J Chem Ecol 33:22182228 doi:10.1007/s10886-007-9376-0

Pinto DM, Himanen SJ, Nissinen A, Nerg AM, Holopainen JK (2008) Host location behavior of Cotesia plutellae Kurdjumov (Hymenoptera: Braconidae) in ambient and moderately elevated ozone in field conditions. Environ Pollut 156:227-231 doi:10.1016/j.envpol.2007.12.009 
Potts SG, Biesmeijer JC, Kremen C, Neumann P, Schweiger O, Kunin WE (2010) Global pollinator declines: trends, impacts and drivers. Trends Ecol Evol 25:345-353 doi:10.1016/j.tree.2010.01.007

445 Rachlin S (1971) Process for preparing isocaryophyllene. US Patent 3621070, 192.14, R448

446 Reinhard J, Sinclair M, Srinivasan MV, Claudianos C (2010) Honeybees learn odour mixtures

447 via a selection of key odorants. PLoS ONE 5:e9110 doi:10.1371/journal.pone.0009110

448 Reissell A, Aschmann SM, Atkinson R, Arey J (2002) Products of the OH radical- and $\mathrm{O}_{3-}$

449 initiated reactions of myrcene and ocimene. J Geophysical Res 107:4138 doi:

450 10.1029/2001JD001234

451 Roderick WR (1966) Current ideas on the chemical basis of olfaction. J Chem Education 452 43:510 doi:10.1021/ed043p510

453 Setiabudi A, Makkee M, Moulijn JA (2004) The role of $\mathrm{NO}_{2}$ and $\mathrm{O}_{2}$ in the accelerated combustion of soot in diesel exhaust gases. Appl Catal B Environ 50:185-194 doi:10.1016/j.apcatb.2004.01.004

Silverstein RM, Young JC (1976) Insects generally use multicomponent pheromones. In: Beroza, M (ed) Pest Management with Insect Sex Attractants; ACS Symposium Series; American Chemical Society: Washington, DC, 1976:1-29

459 Steffan-Dewenter I, Potts SG, Packer L (2005) Pollinator diversity and crop pollination 460 services are at risk. Trends Ecol Evol 20:651-652 doi:10.1016/j.tree.2005.09.004

461 Titov AI (1963) The free radical mechanism of nitration. Tetrahedron 19:557-580

462 doi:10.1016/S0040-4020(01)98544-8

463 Vanbergen AJ, the Insect Pollinators Initiative (2013) Threats to an ecosystem service:

464 pressures on pollinators. Front Ecol Environ11 (5):251-259 doi:10.1890/120126

465 Wright GA, Schiestl FP (2009) The evolution of floral scent: the influence of olfactory learning by insect pollinators on the honest signalling of floral rewards. Funct Ecol 23:841851 doi:10.1111/j.1365-2435.2009.01627.x

468 [www.epa.gov] United States Environmental Protection Agency. National Ambient Air 
470 Table 1 Information about compound purity, vapour pressure, supplier information and their occurrence in seed 471 plant families as reported in Knudsen et al. 2006

Common flower volatile blend

\begin{tabular}{lrcll}
\hline compound & purity $(\%)$ & $\begin{array}{l}\text { vapour pressure } \\
\left(\mathrm{mm} \mathrm{Hg}^{-1} \text { at } 25^{\circ} \mathrm{C}\right)\end{array}$ & supplier & occurrence \\
\hline $\boldsymbol{\beta}$-Pinene & 98 & 2.9300 & Sigma Aldrich $^{\mathrm{a}}$ & $59 \%$ \\
Myrcene & 90 & 2.0900 & Sigma Aldrich $^{\mathrm{a}}$ & $70 \%$ \\
Limonene & 97 & 1.9800 & Sigma Aldrich $^{\mathrm{a}}$ & $71 \%$ \\
$\boldsymbol{\beta}$-Ocimene & $\geq 90$ & 1.5590 & Sigma Aldrich $^{\mathrm{a}}$ & $71 \%$ \\
Benzaldehyde & 99 & 0.1270 & Sigma Aldrich $^{\mathrm{a}}$ & $64 \%$ \\
$\boldsymbol{\beta}$-Caryophyllene & $\geq 80$ & 0.0130 & Sigma Aldrich $^{\mathrm{a}}$ & $52 \%$ \\
Methyl salicylate & $\geq 99$ & 0.0343 & Fluka $^{\mathrm{b}}$ & $57 \%$ \\
Benzyl alcohol & 99 & 0.0940 & Sigma Aldrich $^{\mathrm{a}}$ & $56 \%$ \\
\hline
\end{tabular}

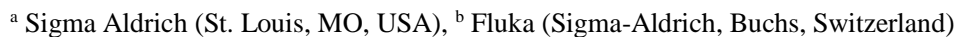


Table 2 Compound composition of the common floral volatile and the oilseed rape blend and their according test stimuli for the proboscis extension response assays

\begin{tabular}{|c|c|c|c|c|}
\hline \multicolumn{5}{|c|}{ Common flower volatile blend } \\
\hline compound & $\mathrm{CFV}$ & CFV-1 & $\mathrm{CFV}-2$ & $\mathrm{CFV}-3$ \\
\hline$\beta$-Pinene & $1 \mu \mathrm{L}$ & $1 \mu \mathrm{L}$ & $1 \mu \mathrm{L}$ & $1 \mu \mathrm{L}$ \\
\hline Myrcene $^{\text {a }}$ & $1 \mu \mathrm{L}$ & $1 \mu \mathrm{L}$ & - & - \\
\hline Limonene & $1 \mu \mathrm{L}$ & $1 \mu \mathrm{L}$ & $1 \mu \mathrm{L}$ & $1 \mu \mathrm{L}$ \\
\hline$\beta$-Ocimene ${ }^{b}$ & $1 \mu \mathrm{L}$ & - & $1 \mu \mathrm{L}$ & - \\
\hline Benzaldehyde & $1 \mu \mathrm{L}$ & $1 \mu \mathrm{L}$ & $1 \mu \mathrm{L}$ & $1 \mu \mathrm{L}$ \\
\hline$\beta$-Caryophyllene ${ }^{c}$ & $1 \mu \mathrm{L}$ & $1 \mu \mathrm{L}$ & $1 \mu \mathrm{L}$ & $1 \mu \mathrm{L}$ \\
\hline Methyl salicylate & $1 \mu \mathrm{L}$ & $1 \mu \mathrm{L}$ & $1 \mu \mathrm{L}$ & $1 \mu \mathrm{L}$ \\
\hline Benzyl alcohol & $1 \mu \mathrm{L}$ & $1 \mu \mathrm{L}$ & $1 \mu \mathrm{L}$ & $1 \mu \mathrm{L}$ \\
\hline dose & $8 \mu \mathrm{L}$ & $7 \mu \mathrm{L}$ & $7 \mu \mathrm{L}$ & $6 \mu \mathrm{L}$ \\
\hline
\end{tabular}


476 Table 3 Diesel exhaust gas composition

\begin{tabular}{lrlr}
\hline gas (unit) & mean & & S.E. \\
\hline Oxygen (\%) & 19.78 & \pm & 0.10 \\
Nitric Oxide (ppm) & 19.84 & \pm & 2.27 \\
Nitrogen Dioxide (ppm) & 17.54 & \pm & 1.25 \\
Sulphur Dioxide (ppm) & 0.00 & \pm & 0.00 \\
Carbon Monoxide (ppm) & 226.84 & \pm & 20.47 \\
\hline
\end{tabular}


Table 4 ANOVA results for single compounds which abundances were significantly decreased by $\mathrm{NO}_{X}$ exposure $479 \quad$ (also see Fig. 4)

\begin{tabular}{llr}
\hline compound & $F$-value & P-value \\
\hline Myrcene & $F_{(3,12)}=11.803$ & 0.001 \\
$Z$ - $\beta$-Ocimene & $F_{(3,12)}=89.226$ & $<0.001$ \\
$E$ - $\beta$-Ocimene & $F_{(3,12)}=96.951$ & $<0.001$ \\
$\beta$-Caryophyllene & $F_{(3,12)}=568.459$ & $<0.001$ \\
Benzyl alcohol & $F_{(3,12)}=9.184$ & 0.002 \\
\hline
\end{tabular}

480 
Fig. 1 Harnessed honey bee ready for PER assay

Fig. 2 Total ion current (TIC) chromatogram of the common flower volatile under 30min ambient air and diesel exhaust exposure. Consecutive numbers represent the following chemical compounds: $\beta$-Pinene (1), myrcene (2), limonene (3), $Z$ - $\beta$-ocimene (4a), $E$ - $\beta$-ocimene (4b), benzaldehyde (5), $\beta$-caryophyllene (6a), isocaryophyllene (6b) methyl salicylate (7), benzyl alcohol (8).

Fig. 3 Proboscis extension response assay results representing the ability of honey bees to recognize the common floral volatile (CFV) blend, CFV blend without $\beta$-ocimene (CFV-1), $\mathrm{CFV}$ blend without myrcene (CFV-2), and CFV blend without both (CFV-3). The response to the test stimuli was compared to the response to the full blend. A Bonferroni correction was applied, and all significant differences are indicated with an asterisk at a 0.016 level of significance

Fig. 4 The effect of 30min exposures of different nitrogen oxides $\left(\mathrm{NO}_{X}=\mathrm{NO}\right.$ and $\mathrm{NO}_{2}$ at a $1: 1$ ratio) concentrations on the abundance of all floral compounds used in this study. Bars represent the average peak area $( \pm$ S.D). Different lowercase letters indicate a statistically significant difference. 
Fig. 1 


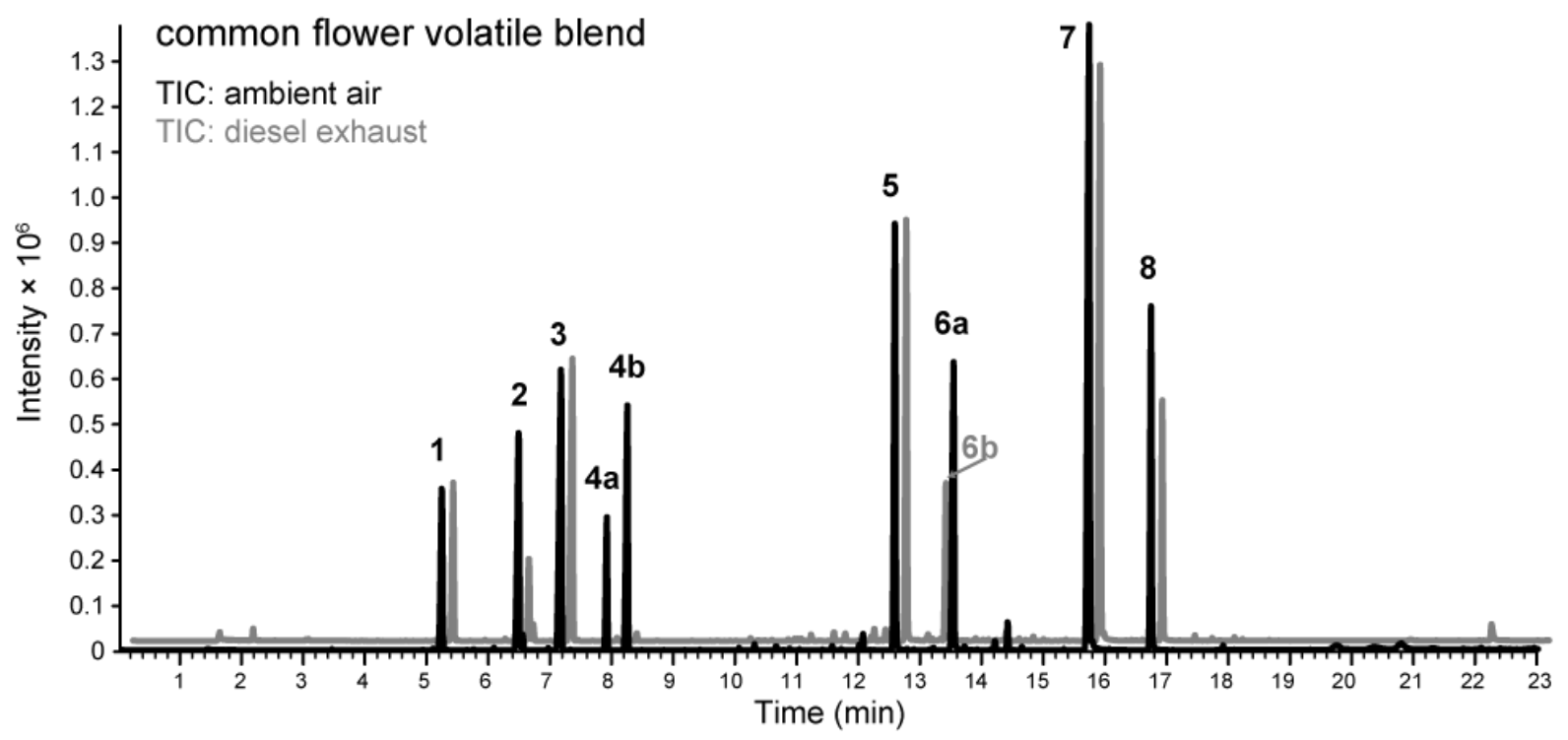

503

504

Fig. 2

505 


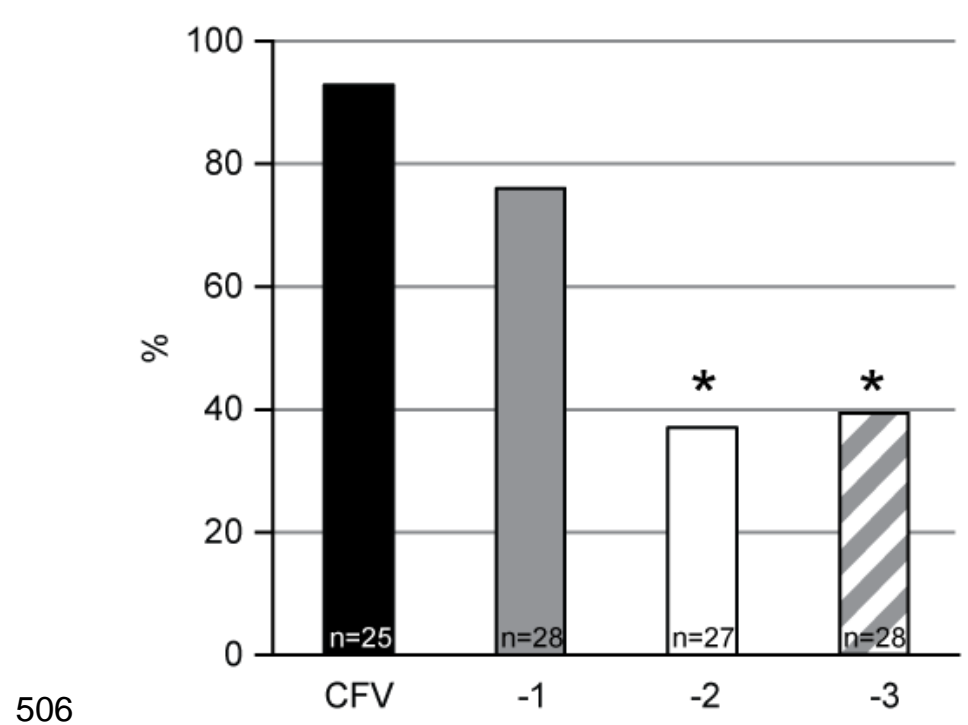

507 Fig. 3

508 


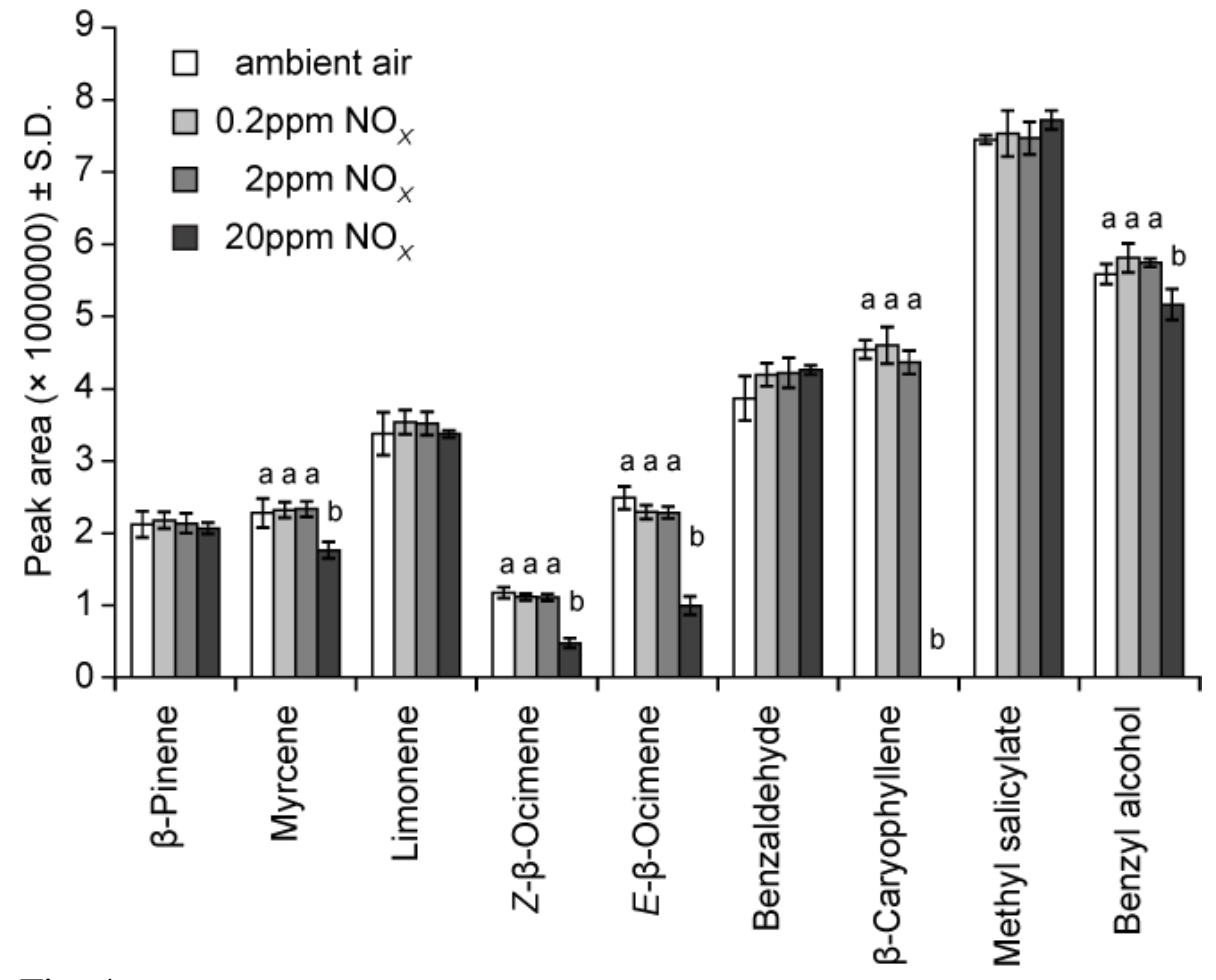

$510 \quad$ Fig. 4 